\title{
Response of malnourished babies to heat
}

\author{
O. G. BROOKE and CARMENCITA B. SALVOSA \\ From the Tropical Metabolism Research Unit, University of the West Indies, Kingston, Jamaica
}

\begin{abstract}
Brooke, O. G., and Salvosa, C. B. (1974). Archives of Disease in Childhood, 49, 123. Response of malnourished babies to heat. Twelve seriously malnourished Jamaican babies were investigated before and after treatment to discover whether they were unduly susceptible to heat in the malnourished state. On exposure to an environmental temperature of $38^{\circ} \mathrm{C}$ at low humidity their mean rectal temperature increased at a rate of $0.75^{\circ} \mathrm{C} /$ hour when they were malnourished, while after recovery it showed little change. During heat exposure total evaporative water loss in the recovered children was, on average, $44 \%$ greater than it was in the malnourished state, and in the malnourished children there was a significant inverse relation between total evaporative water loss and rise in rectal temperature. Measured sweat loss under a ventilated capsule after an intradermal diaphoretic injection in 7 of the children confirmed that sweating was impaired when they were malnourished. Rectal and skin temperatures at sweat onset were unchanged after recovery, indicating that central homoeostatic mechanisms were probably not disturbed. Peripheral vasodilatation in response to heat was unimpaired. Children with severe skin lesions had the most defective sweating, and malnutrition may damage the sweat glands as it does the hair follicles. It is very important to nurse malnourished children at the correct temperature; an environmental temperature of about $29^{\circ} \mathrm{C}$ is satisfactory in most cases.
\end{abstract}

It is a well-known but poorly documented clinical observation that malnourished children may run intermittent low-grade fever for which no infective cause can be found (Underwood Ground, 1954; Kahn, Rand, and Walker, 1954). Faulty adaptation to heat stress was proposed as the reason for the increased rate of summer admissions among children with kwashiorkor in Johannesburg (Wayburne, 1968), and in heated wards in Pretoria hyperthermia is more common than hypothermia in malnourished children (Wharton, 1968), the reverse of the usual findings in Africa or Jamaica (Staff, 1968; Brooke, 1972a). This increased susceptibility to heat has received little attention. Kahn and his co-workers (1954) measured sweat production under an absorbant patch on the anterior abdominal wall in oedematous malnourished children who were exposed to heat. They found that it was reduced compared with normal controls, but this method of testing may not reflect the overall capacity for evaporative heat loss. They did not study children with non-oedematous malnutrition (marasmus) or examine the possible relation between the presence of skin lesions and impairment of sweating. In

Received 1 August 1973.
Jamaica most children with malnutrition have mild oedema or none at all, while moderate-severe skin changes are common (Alleyne, 1970). We have studied 12 malnourished children, only one of whom had generalized oedema, before and after recovery to see whether their physiological responses to heat were impaired, particularly in those with widespread skin lesions. Defective sweating would have important implications for the nursing care of these children in tropical climates.

\section{Patients and methods}

The children who were studied were all seriously malnourished on admission to the Tropical Metabolism Research Unit. They were selected to exclude any with fever or more than trivial infection. Clinical details are given in the Table. Only one child had generalized oedema, indicated by the symbol ++ . They averaged $49 \%$ of their expected weight for age and $77 \%$ of their expected weight for height on admission, and averaged $70 \%$ and $103 \%$ of these parameters on discharge (Boston standards, Nelson, 1969). The children were studied within 72 hours of admission to the unit and again on recovery, when they had reached their expected weight for height.

Two kinds of studies were done. In the first the babies were placed naked (except for a plastic urine 
TABLE

Clinical details of 12 malnourished Jamaican children

\begin{tabular}{|c|c|c|c|c|c|c|c|c|c|}
\hline Case no. & Sex & $\begin{array}{l}\text { Age on } \\
\text { admission } \\
\text { (mth) }\end{array}$ & $\begin{array}{l}\text { Weight on } \\
\text { admission } \\
\quad(\mathrm{kg})\end{array}$ & $\begin{array}{l}\text { Height on } \\
\text { admission } \\
\text { (cm) }\end{array}$ & Oedema ${ }^{\star}$ & $\begin{array}{l}\text { Skin and } \\
\text { hair changes } \\
\text { (graded)t }\end{array}$ & $\begin{array}{l}\text { Weight on } \\
\text { recovery } \\
(\mathrm{kg})\end{array}$ & $\begin{array}{l}\text { Height on } \\
\text { recovery } \\
(\mathrm{cm})\end{array}$ & $\begin{array}{l}\text { Age on } \\
\text { recovery } \\
\text { (mth) }\end{array}$ \\
\hline $\begin{array}{r}1 \\
2 \\
3 \\
4 \\
5 \\
6 \\
7 \\
8 \\
9 \\
10 \\
11 \\
12 \\
\text { Mean }\end{array}$ & $\begin{array}{c}\text { M } \\
F \\
F \\
M \\
F \\
F \\
F \\
F \\
M \\
M \\
F \\
M\end{array}$ & $\begin{array}{r}5 \cdot 3 \\
10 \cdot 1 \\
10 \cdot 7 \\
6 \cdot 0 \\
9 \cdot 6 \\
6 \cdot 2 \\
6 \cdot 2 \\
13 \cdot 0 \\
16 \cdot 3 \\
8 \cdot 4 \\
6 \cdot 1 \\
4 \cdot 0 \\
\\
8 \cdot 5\end{array}$ & $\begin{array}{l}4 \cdot 97 \\
5 \cdot 02 \\
4 \cdot 36 \\
5 \cdot 19 \\
3 \cdot 86 \\
3 \cdot 82 \\
2 \cdot 42 \\
7 \cdot 38 \\
5 \cdot 04 \\
4 \cdot 43 \\
3 \cdot 13 \\
3 \cdot 39 \\
4 \cdot 42\end{array}$ & $\begin{array}{l}65 \cdot 0 \\
63 \cdot 5 \\
62 \cdot 5 \\
64 \cdot 0 \\
57 \cdot 5 \\
51 \cdot 5 \\
49 \cdot 5 \\
68 \cdot 7 \\
64 \cdot 0 \\
65 \cdot 5 \\
52 \cdot 0 \\
51 \cdot 5 \\
59 \cdot 6\end{array}$ & $\begin{array}{c}0 \\
0 \\
0 \\
0 \\
0 \\
0 \\
0 \\
++ \\
0 \\
0 \\
+ \\
+\end{array}$ & $\begin{array}{l}0 \\
3 \\
3 \\
4 \\
0 \\
1 \\
1 \\
2 \\
0 \\
4 \\
2 \\
4\end{array}$ & $\begin{array}{r}7 \cdot 78 \\
7 \cdot 31 \\
6 \cdot 15 \\
8 \cdot 47 \\
6 \cdot 40 \\
6 \cdot 18 \\
4 \cdot 63 \\
10 \cdot 26 \\
8 \cdot 67 \\
8 \cdot 30 \\
5 \cdot 84 \\
4 \cdot 89 \\
7 \cdot 07\end{array}$ & $\begin{array}{l}68 \cdot 0 \\
65 \cdot 0 \\
65 \cdot 0 \\
66 \cdot 0 \\
62 \cdot 5 \\
59 \cdot 0 \\
54 \cdot 0 \\
70 \cdot 5 \\
67 \cdot 0 \\
73 \cdot 0 \\
58 \cdot 0 \\
56 \cdot 0 \\
63 \cdot 7\end{array}$ & $\begin{array}{r}8 \cdot 7 \\
11 \cdot 3 \\
13 \cdot 3 \\
7 \cdot 5 \\
11 \cdot 6 \\
8 \cdot 3 \\
8 \cdot 3 \\
14 \cdot 5 \\
17 \cdot 8 \\
10 \cdot 3 \\
7 \cdot 7 \\
5 \cdot 5 \\
10 \cdot 4\end{array}$ \\
\hline
\end{tabular}

$\star++$, generalized oedema; + , oedema of legs; 0 , none.

† Grading of skin and hair changes: 0 , no changes; 1 , hair changes only; 2 , mild skin lesions (dyspigmentation, scaling); 3 , generalized skin changes with pigmentary changes and desquamation; 4, severe generalized lesions with ulceration.

collection bag) and lightly sedated with paraldehyde on a nylon mesh sling in a metabolic chamber (Brooke, 1972b) where the environmental temperature was within the thermoneutral range $\left(29^{\circ} \mathrm{C} \pm 0.5^{\circ} \mathrm{C}\right)$. Tests had been carried out previously to ensure that paraldehyde did not induce sweating as chloral hydrate does, and the most satisfactory dose was found to be $0.3 \mathrm{ml} / \mathrm{kg}$ by enema. This was adhered to in all the studies. Results were abandoned if the child awoke and cried, but not if he remained quiet. Studies were begun at least 4 hours after the last meal. Baseline measurements of total evaporative water loss by wet-and-dry bulb thermometry (Brooke, 1972b), rectal temperature, skin temperature, pulse rate, and peripheral blood flow were made during a half-hour at neutral temperature. The environmental temperature was then raised over a period of 45 minutes to $38{ }^{\circ} \mathrm{C}\left( \pm 0.3{ }^{\circ} \mathrm{C}\right)$, a not unreasonable temperature in the tropics. Measurements were repeated at regular intervals during this period and for a half-hour after stabilization at the high temperature. Water vapour pressure of the air entering the chamber was maintained at $9.8 \mathrm{mmHg} \pm 2 \%$. Airflow was $501 . / \mathrm{min}$. Rectal temperature was measured with a thermistor inserted 4-6 $\mathrm{cm}$ into the rectum. Skin temperature was measured with 36 s.w.g. thermocouples secured with adhesive tape. Measurements were made on the forehead, dorsal surface of left forearm, anterior abdominal wall, and lateral surface of left thigh. Mean skin temperature was calculated from weightings based on the proportions of a 9-month-old child (Le Gros Clark and Medawar, 1945). Pulse rate was measured with a Devices photoelectric pulse monitor applied to the palmar surface of a thumb. This instrument was also used to give an estimate of skin blood flow (Hertzman, 1948; Fox, 1968). The skin blood flow was measured simultaneously on the dorsal surface of the right hand by the heat flow method, using a miniature calorimeter (Fox, Goldsmith, and Kidd, 1962). Only one child had oedema of the hands (Case 8).
In the second series of studies sweat production was measured under a ventilated capsule in Cases 6 to 12, after intradermal injection of $0.025 \mathrm{mg}$ carbachol. The capsule, which covered an area of $9 \mathrm{~cm}^{2}$, was held to the lateral surface of the right mid-thigh with rubber bands. Dry air was drawn through the capsule at a constant measured rate for 30 minutes before and 30 minutes after the diaphoretic injection. Water that evaporated from the skin surface during these periods was removed from the air in a concentrated $\mathrm{H}_{2} \mathrm{SO}_{4}$ bubbler and measured by accurate weighing. These studies were carried out in duplicate at room temperature which, during the period of the studies, did not exceed $30^{\circ} \mathrm{C}$.

During recovery in the unit the babies were not subjected to any other thermal stresses which might have produced unusual heat acclimatization.

Maternal consent was obtained for all the studies.

\section{Results}

Total evaporative water loss, body temperature, and blood flow measurements in a hot environment. Fig. 1 shows the changes in rectal temperature and total evaporative water loss during warming. Rectal temperatures increased rapidly in the malnourished children, rising in 85 minutes from $36.87{ }^{\circ} \mathrm{C}$ (SD 0.37 ) to $37.93{ }^{\circ} \mathrm{C}$ (SD $0 \cdot 36$ ), a rate of $0.75{ }^{\circ} \mathrm{C} /$ hour. When they had recovered, their rectal temperatures rose from $37 \cdot 27{ }^{\circ} \mathrm{C}$ (SD $0 \cdot 23$ ) to $37 \cdot 61{ }^{\circ} \mathrm{C}(\mathrm{SD} 0 \cdot 25)$ during the same heat stress, an increase of only $0.34{ }^{\circ} \mathrm{C}$. In neutral conditions at the beginning of the studies the children's rectal temperatures were on average $0.37{ }^{\circ} \mathrm{C}$ lower when they were malnourished than when they had recovered $(t=3 \cdot 7, P<0 \cdot 01$, paired comparison). After a half-hour at raised environmental temperature their mean rectal temperature 


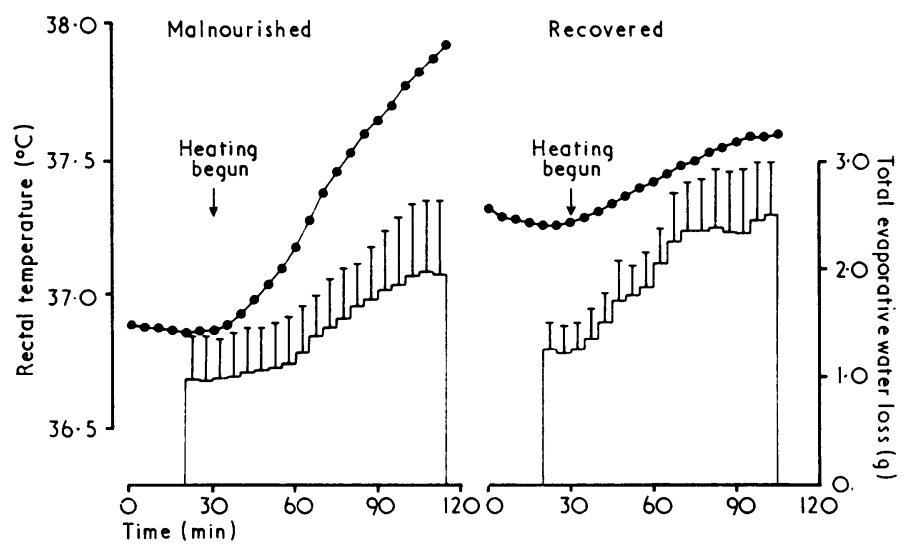

FIG. 1.-Mean change in rectal temperature and total evaporative water loss in the 12 children during exposure to environmental temperature of $38^{\circ} \mathrm{C}$ when malnourished and after recovery. Bars indicate SDs.

was $0.33{ }^{\circ} \mathrm{C}$ higher when they were malnourished than it was after recovery $(t=2 \cdot 5, P<0 \cdot 05)$.

After recovery the children had greater total evaporative water loss, both before and during exposure to heat. In the final half-hour of warming this amounted to a mean percentage increase of $44 \%$ over the values obtained in the malnourished state. This was significant $(t=2 \cdot 3, P<0.05)$. Three babies (Cases 4, 10, and 12) had virtually no sweating when they were malnourished. These 3 all had severe dermatoses.

In the malnourished state there was a significant inverse relation between total evaporative water loss and rise in rectal temperature. This is shown in

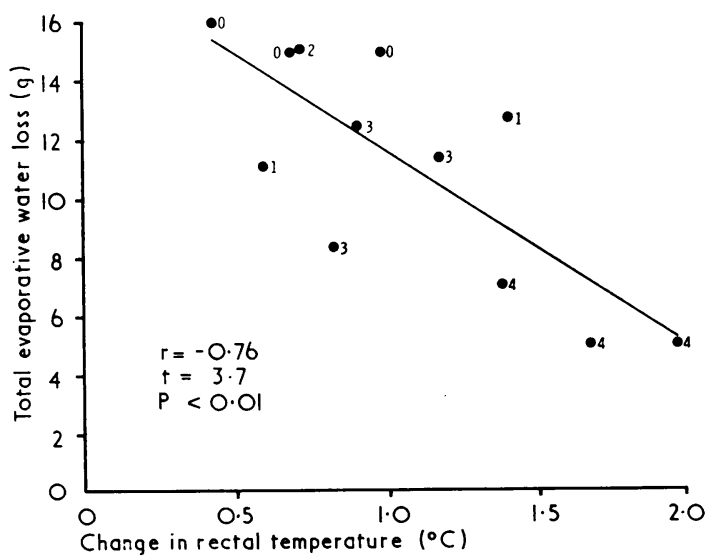

Fig. 2.-Relation between change in rectal temperature and total evaporative water loss during a half-hour exposure to environmental temperature of $38^{\circ} \mathrm{C}$ in the 12 malnourished children. Numbers indicate grading of skin lesions (see Table).
Fig. 2. Also shown in Fig. 2 is the extent of skin involvement by malnutrition dermatosis in each case. There is a tendency for sweat production to decrease as skin lesions become more severe.

We examined body temperature in relation to sweat onset in case the nervous mechanisms concerned with the control of sweating were disturbed. Sweat onset was easy to determine in the individual cases because there was always a simultaneous sharp rise in total evaporative water loss. These changes become smoothed out in the histogram of the mean evaporation shown in Fig. 1. Mean rectal temperature at sweat onset in the malnourished state was $37.30^{\circ} \mathrm{C}$, and after recovery it was $37 \cdot 32^{\circ} \mathrm{C}$, which is not significantly different. Neither was there a significant difference in the mean skin temperature at sweat onset, which was $36.59^{\circ} \mathrm{C}$ when the children were malnourished and $36.22{ }^{\circ} \mathrm{C}$ when they had recovered.

Changes in peripheral blood flow are shown in Fig. 3. Both methods of measurement showed a slightly greater increase in the malnourished than in the recovered children. By the photoelectric method the difference was $13 \cdot 2 \%$ during the last half-hour of warming $(t=2 \cdot 2, P=0 \cdot 05)$, and by the heat flow method it was $12 \cdot 5 \%(t=2 \cdot 7$, $P<0.05)$. We do not know whether the greater flow in the malnourished children is biologically significant or whether it is an artifact caused by thinning of the skin and subcutaneous tissues. At any rate there was probably no impairment of the vasodilator response to heat in the malnourished state. The rapid onset of vasodilatation in both malnourished and recovered children is the result of whole body warming and contrasts with the much slower response generally found in adults when 

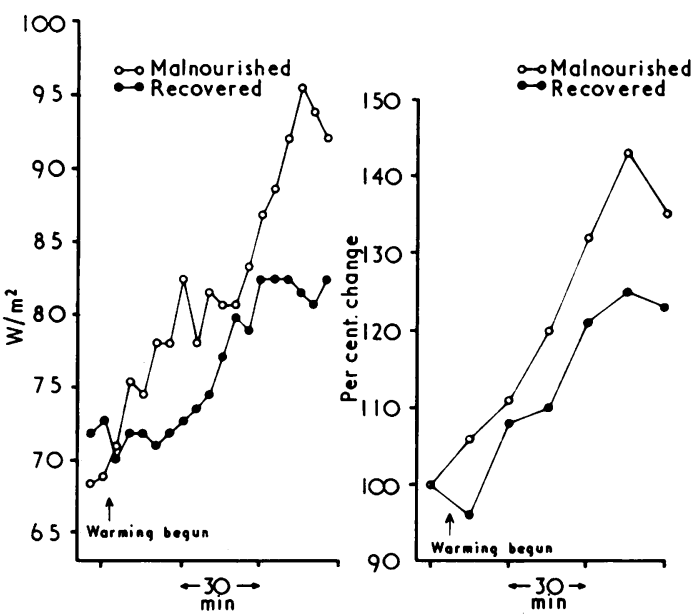

FIG. 3.-Changes in peripheral blood flow during exposure to environmental temperature of $38^{\circ} \mathrm{C}$ in the 12 children when malnourished and after recovery. On the left are the results using the heat flow method (watts $\left./ \mathrm{m}^{2}\right)$; on the right results using the photoelectric pulse monitor.

peripheral heating is used. Mean pulse rate in the malnourished children increased from 108 to 134 beats/min during the period of warming. After recovery it increased from 116 to 127 beats/min.

Sweat production under the ventilated capsule. Fig. 4 shows the percentage increase in evaporative water loss after the intradermal diaphoretic injection. The mean increase in the malnourished state was $168 \%$ (SD 94). After recovery it was $446 \%$ (SD 230). The latter represents a significant increase in the sweat response $(t=3 \cdot 1, P<0 \cdot 02)$. In general, the malnourished children with clinically significant skin lesions had the lowest sweating response.

\section{Discussion}

The malnourished children whom we studied were intolerant of heat and their body temperatures rose rapidly during exposure to heat in spite of their nakedness and the low humidity in the chamber which favoured the evaporation of sweat. This was mainly due to defective sweat production, since peripheral blood flow increased to a greater extent in the malnourished state than it did after recovery. The malnourished child has the additional disadvantage that his thermal capacity and tissue insulation are reduced (Brooke, 1973), and hence a high environmental temperature imposes a greater stress than it does in a normal child of similar age.

Our observations on the peripheral vasomotor

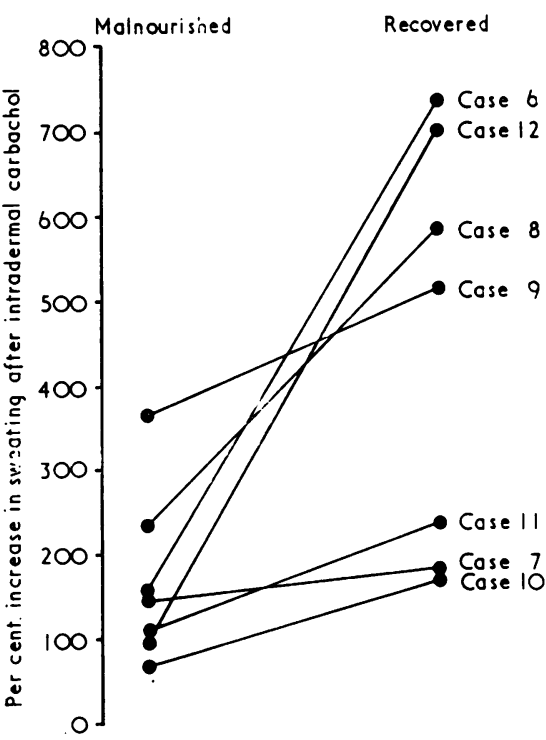

Fig. 4.-Sweat response to intradermal diaphoretic injection under ventilated capsule in 7 malnourished children, before and after treatment.

responses of these children make it unlikely that the impairment of sweating is due to poor skin blood flow as suggested by Kahn et al. (1954). Nor can it be attributed to oedema as it has been in congestive heart failure (Burch, 1946), since most of the children had little or no oedema. The set-point for sweat onset was evidently not altered in our children, so it seems that the functioning of the sweat glands themselves is probably at fault. Support for this is given by the finding that in general the children with the worst dermatoses sweated the least, both during body heating and after diaphoretic injection. Morphological changes in sweat glands of malnourished children have not been reported but Rangam, Bhagwat, and Gupta (1962), in a series of skin biopsies from 31 children with kwashiorkor, commented that sweat glands were infrequently seen and those that were had surrounding collections of histiocytes. The significance of these observations is not clear but it is reasonable to suppose that a nutritional insult which is capable of disturbing pigment formation and the function of hair follicles would also affect other specialized skin components. An electron microscopical study of sweat gland structure in malnourished children might throw more light on this. It is of interest that two children (Cases 6 and 7) who had hair changes but no visible dermatosis sweated less than the 3 other children who had neither skin nor hair changes 
(Cases 1, 5, and 9), so sweat function may be a sensitive indication of the effects of malnutrition on the skin.

In the light of these findings it is of importance to ensure that malnourished children are not exposed to high ambient temperatures, particularly direct tropical sunlight, since pyrexia will quickly result. As these children are also susceptible to cold (Staff, 1968; Brooke, 1972a), it becomes critical to ensure that they are nursed at the correct temperature, and there is evidence from our own observations (unpublished) and those of Kulin and Kiss-Szabó (1966) that an environmental temperature of about $29^{\circ} \mathrm{C}$ is suitable in most cases.

C.B.S. is in receipt of a WHO fellowship.

\section{REFERENCES}

Alleyne, G. A. O. (1970). Some features of infantile malnutrition in Jamaica. West Indian Medical fournal, 19, 32.

Brooke, O. G. (1972a). Hypothermia in malnourished Jamaican children. Archives of Disease in Childhood, 47, 525 .

Brooke, O. G. (1972b). A simple metabolism chamber allowing determinations of evaporative water loss in large babies. West Indian Medical Fournal, 21, 232.

Brooke, O. G. (1973). Thermal insulation in malnourished Jamaican children. Archives of Disease in Childhood, 48, 901.

Burch, G. E. (1946). Influence of environmental temperature and relative humidity on the rate of water loss through the skin in congestive heart failure in subtropical climate. American fournal of the Medical Sciences, 211, 181.

Fox. R. H. (1968). Effects of cold on the extremities. Proceedings of the Roy'al Society of Medicine, 61, 785.
Fox, R. H., Goldsmith, R., and Kidd, D. J. (1962). Cutaneous vasomotor control in the human head, neck and upper chest. fournal of Physiology, 161, 298.

Hertzman, A. B. (1948). Photoelectric plethysmography of the skin. In Methods in Medical Research, Vol. 1, p. 177. Year Book Medical Publishers, Chicago.

Kahn, R., Rand, M. D., and Walker, A. R. P. (1954). Impairment of sweat secretion in malnourished infants. Pediatrics, 14, 659.

Kulin, L., and Kiss-Szabó, A. (1966). Determination of the thermoneutral environment of marasmic infants. Acta Paediatrica Academiae Scientiarum Hungaricae, 7, 105.

Le Gros Clark, W. E., and Medawar, P. B. (Eds.) (1945). Essays on Growth and Form. Clarendon Press, Oxford.

Nelson, W. E. (1969). Textbook of Paediatrics, 9th ed., p. 40. Ed. by W. E. Nelson, V. C. Vaughan, and R. J. McKay. Saunders, Philadelphia and London.

Rangam, C. M., Bhagwat, A. G., and Gupta, J. C. (1962). Cutaneous lesions in kwashiorkor. A histopathological and histochemical study. Indian fournal of Medical Research, 50, 184.

Staff, T. H. E. (1968). Treatment of severe kwashiorkor and marasmus in hospital. East African Medical fournal, 45, 399.

Underwood Ground, K. E. A. (1954). Kwashiorkor in Basutoland. In Malnutrition in African Mothers, Infants and Young Children, p. 52. Colonial Office Report of the 2nd Inter-African Conference on Nutrition, Fajara, Gambia, 1952. H.M.S.O., London.

Wayburne, S. (1968). Malnutrition in Johannesburg. In Calorie Deficiencies and Protein Deficiencies. Proceedings of a Colloquium held in Cambridge, April 1967, p. 13. Ed. by R. A. McCance and E. M. Widdowson. Churchill, London.

Wharton, B. A. (1968). Difficulties in the initial treatment of kwashiorkor. In Calorie Deficiencies and Protein Deficiencies. Proceedings of a Colloquium held in Cambridge, April 1967, p. 156. Ed. by R. A. McCance and E. M. Widdowson. Churchill, London.

Correspondence to Dr. O. G. Brooke, Department of Paediatrics, St. Mary's Hospital, London W.2. 